(C) 2018 This manuscript version is made available under the CC-BY-NC-ND 4.0 license http://creativecommons.org/licenses/ by-nc-nd/4.0/

\title{
The impact of sulfite ions on barium sulfate crystallization
}

\author{
Franca Jonesł*, Mark I. Ogden*, Tomoko Radomirovic*
}

$\dagger$ corresponding author

\section{ABSTRACT.}

In this manuscript we investigate an inorganic, anionic promoter of barium sulfate crystallization. Sulfite ions are found to promote barium sulfate crystallization at low concentrations. Turbidimetric experiments show homogenous nucleation promotion and AFM results show possible 2D nucleation promotion in the presence of sulfite ions. Growth promotion appears to be mainly in the $c$-axis relative to the other faces according to morphology results at low S values. Analysis of the sulfite ion impact by assuming it completely oxidizes to sulfate did not adequately explain all experimental results, suggesting that these ions also interact in some other way. One mechanism by which sulfite might promote barium sulfate crystallization is by promoting de-solvation of the barium ion by weakly complexing with it.

* Curtin University, GPO Box U1987, Perth WA 6845 Australia.

Phone: +61892667677 Fax: +61892664699 email: F.Jones@curtin.edu.au

KEYWORDS: A1 Impurities; B1 Barium compounds; A2 growth from solution; A1 nucleation; A1 crystal morphology.

\section{INTRODUCTION}

Scale is defined as unwanted crystallization, and the unwanted aspect can be either that crystallization occurs or it can be where in the process it occurs. For example, in the refining of bauxite, aluminium trihydroxide is precipitated as the product but it can also be a scale formed during the thickening 
operation [1]. Scale can lead to many undesired consequences such as loss of production, loss of product purity and maintenance issues to name but a few [2-5]. Barium sulfate is a well-known scale compound [2-5] but it is also a relatively simple crystallization system that can be used as a model system. For this reason, we have used barium sulfate to investigate the impact of functional group [6], lattice matching [7] and charge effects [8] on crystallization processes. Despite years of investigating barium sulfate and other inorganic systems describing the effect of various organics on the precipitation of different solids (for example [9-11]), there are still many fundamental questions to be answered in this area before the effect of additives can be predicted and their rational design for specific systems can be accomplished $a$ priori.

A new and exciting area of research is that of crystallization promotion. Crystallization promotion has been observed for calcium carbonate in the presence of polyaspartic molecules [12]. It has also been observed for barium sulfate in the presence of aspartic acid [13], and the alkali metals [14-16]. In the case of aspartic acid, it has been suggested that the mode of action was to weakly complex the barium ion so that it was partially de-solvated, aiding the incorporation of the barium ion into the lattice structure. This is supported by the finding that barium ion de-solvation is a rate-determining step in barium sulfate crystallization [13, 17]. AFM studies further corroborate this method of action by showing that non-stoichiometric composition in favour of barium ions (i.e. $\mathrm{Ba}^{2+} / \mathrm{SO}_{4}{ }^{2-}>1$ ) results in faster growth rates for the (001) face [15]. Inorganic anions are seldom investigated as impurities for barium sulfate crystallization and then usually only to determine solid solution formation[18,19]. Carbonate $\left(\mathrm{CO}_{3}{ }^{2-},[20]\right)$ is the main inorganic anion (other than the halogens reported in [14-16]) that has been investigated. It was found that carbonate inhibits barium sulfate crystallization. The halogens [14-16] were found to generally promote growth rates. As far as the authors are aware of, there are no other reported inorganic, anionic promoters of barium sulfate.

This manuscript aims to investigate the impact of another sulfur containing anion on the process of barium sulfate crystallization. The rational behind the choice of this ion is that the sulfite ion is slightly stereochemically different to sulfate but has the same formal charge. One complication is that the sulfite 
ion can oxidise to sulfate in solution, however, this aspect can be used to advantage in that a comparable control can in many cases be easily achieved. Another issue is the possible conversion or loss of sulfite ions as $\mathrm{SO}_{2}$ gas through bisulfite. However, if conversion to $\mathrm{SO}_{2}$ is significant, then the impact of sulfite on barium sulfate crystallization should be negligible.

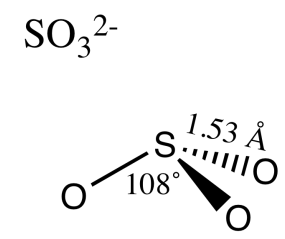

(a)

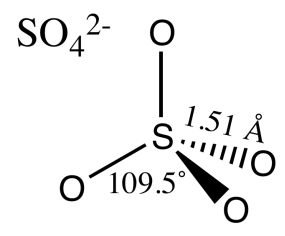

(b)

Figure 1. Comparison of stereochemistry of the (a) sulfite ion (b) sulfate ion according to [21].

\section{EXPERIMENTAL}

The materials used in this study were AR grade, from Ajax Chemicals or BDH and were dissolved to the required concentrations using ultrapure $(>18 \mathrm{M} \Omega \mathrm{cm}$ resistivity) water. Filtered water $(0.2 \mu \mathrm{m})$, having a resistivity of $\geq 18 \mathrm{M} \Omega \mathrm{cm}$, was used throughout. Sodium sulfite (AR grade), was prepared daily at a concentration of $1000 \mathrm{ppm}$ in water as required. All additives were added to the barium chloride solution prior to sulfate being added to commence the crystallization reaction at the desired concentration.

\subsection{Conductivity}

Unseeded, de-supersaturation curves at $25{ }^{\circ} \mathrm{C}$ were monitored using conductivity (WTW LF 197 Conductivity meter) as per previous reports $[6,8,22-26]$. The method of barite precipitation consisted of equilibrating $0.249 \mathrm{mM} \mathrm{BaCl} 2$ and adding 1 mol equivalent of $\mathrm{Na}_{2} \mathrm{SO}_{4}$ solution to initiate crystallization [24]. The total volume for all experiments was $201 \mathrm{~mL}$. The $\mathrm{pH}$ for all experiments was 6.0 except where specified. The de-supersaturation rate was found to have an error of $\sim 10 \%$. The 
supersaturation calculated in this manuscript uses the PHREEQC program [27] to calculate the ion activity product, and then this is used to determine the supersaturation $\mathrm{S}$ such that:

$$
\mathrm{S}=\sqrt{ }\left(\mathrm{IAP} / \mathrm{K}_{\mathrm{sp}}\right)
$$

The rate is also normalized according to:

$$
\text { Normalised rate }=\mathrm{k} / \mathrm{k}_{0}
$$

where $\mathrm{k}_{0}$ is the de-supersaturation rate (in the linear region of the curve) for the control run (absence of impurity) and $\mathrm{k}$ is the de-supersaturation rate for the experiment with impurity present. When sulfite was assumed to oxidise, the sulfate concentration was increased to the level expected for complete oxidation of sulfite and the new supersaturation value calculated in PHREEQC [27] for this concentration. For normalization of the de-supersaturation rate when complete oxidation was assumed, the control de-supersaturation value at the newly calculated S value was used.

\subsection{Light Scattering measurements}

Absorbance was measured using a UV-Vis instrument (GCB) operated at $900 \mathrm{~nm}$ wavelength using a quartz flow cell. When absorbance by the solution and solids is low, this is equivalent to measuring the turbidity (or light scattered) of a system [28]. The induction time is defined as the time prior to the turbidity exceeding background levels and is related to the inverse of nucleation rate for that system [29]. For the barite precipitation experiments, the barium chloride concentration, sodium sulfate concentrations and temperature were all equivalent to those used in the conductivity experiments. The flow rate through the cell was measured at $67 \mathrm{~mL} / \mathrm{min}$ and this was achieved using a Masterflex ${ }^{\circledR}$ peristaltic pump and Tygon ${ }^{\circledR}$ tubing.

\subsection{Morphology and Scanning Electron Microscopy (SEM)}

Morphology experiments were conducted in $25 \mathrm{~mL}$ glass vials. Glass cover slips, cleaned with ethanol and then water, were dried prior to adding to the glass vial. Water and barium chloride stock solution (volume depended on the desired concentration) was added before equilibration to room 
temperature after which a sodium sulfate solution (equimolar amounts of $\mathrm{Ba}^{2+}$ and $\mathrm{SO}_{4}{ }^{2-}$ ) was added to commence the crystallization reaction. The total volume was $20.1 \mathrm{~mL}$ for all experiments, the $\mathrm{pH} 6$ and the inorganic impurity added prior to sulfate addition as per the conductivity experiments. The glass cover slips were collected after 3 days and dried using an absorbent tissue to remove excess solution before placing onto a carbon coated SEM stub. Carbon paint was applied to the edges of the glass cover slip to minimize charging effects.

Solids from conductivity runs were collected by filtration onto $0.22 \mu \mathrm{m}$ membranes and this membrane can be seen in the background of the SEM image as a porous structure. After washing and drying in a desiccator, a portion of the filter paper was placed onto carbon-coated stubs and stored in a desiccator. The samples were gold sputtered prior to viewing using a Philips XL30 SEM or a Zeiss Evo $\mathrm{SEM}$ at $15 \mathrm{kV}$.

\subsection{Atomic Force Microscopy (AFM)}

AFM experiments were performed on a PicoPlus using a standard silicon nitride cantilever with a flow through cell attachment. The same procedure was used for all samples. A freshly cleaved barium sulfate mineralogical sample was fixed to a metallic stub and the flow cell was flushed with filtered (Gelman $0.2 \mu \mathrm{m}$ Supor $^{\circledR}$ membrane filters) ultrapure water (resistivity $>18 \mathrm{M} \Omega \mathrm{cm}$ ) using a precision dual syringe pump run at $0.2 \mathrm{~mL} / \mathrm{min}$. One syringe then had the water replaced with barium chloride solution $(0.1 \mathrm{mM})$ and the other with sodium sulfate solution $(0.1 \mathrm{mM})$. This was then flushed through the cell at a rate of $0.2 \mathrm{~mL} / \mathrm{min}$ as per the water. Finally, the barium chloride solution was replaced with a solution containing barium chloride plus the impurity of interest at a known concentration and the sodium sulfate solution was topped up as necessary. This was then flushed through the cell at a rate of $0.2 \mathrm{~mL} / \mathrm{min}$ as per the water and pure barium sulfate run. In this way, the rate of growth of the original barium sulfate could be measured and the difference to when impurity was added could be gauged. 


\subsection{Oxidation of sulfite to sulfate}

Oxidation of sulfite to sulfate is expected to occur due to $\mathrm{O}_{2}$ being present in water according to the following reaction $[30]$ :

$$
\mathrm{SO}_{3}{ }^{2-}(\mathrm{aq})+1 / 2 \mathrm{O}_{2}(\mathrm{~g}) \leftrightarrows \mathrm{SO}_{4}{ }^{2-}(\mathrm{aq})
$$

However data on this process is somewhat lacking. Most of the literature actually focuses on the dissolution of sulfur dioxide gas into water from an atmospheric viewpoint (see conversion of sulfite to $\mathrm{SO}_{2}$ section). The concentration of dissolved oxygen in water at $25{ }^{\circ} \mathrm{C}$ is expected to be $\sim 1.27 \mathrm{mM}$ [31]. The only applicable data found by us, [32], suggests that at the low levels investigated in this manuscript, oxidation can be described by a first order kinetic equation and should occur with a rate constant of $\sim 0.009 \mathrm{hr}^{-1}$. For a concentration of $0.056 \mathrm{mM}$, this correlates to $\sim 0.0005 \mathrm{mM}$ sulfate/hr being produced, while at $0.08 \mathrm{mM}$ this is $0.0007 \mathrm{mM} / \mathrm{hr}$. As a guide, at a supersaturation of $\mathrm{S}=18.8$ the initial sulfate concentration is $0.25 \mathrm{mM}$ and if $0.05 \mathrm{mM}$ sulfite were added, after an hour this concentration would be expected to increase to $0.2505 \mathrm{mM}$. Thus, oxidation appears to be slow in this system.

\subsection{Conversion of sulfite to $\mathrm{SO}_{2}$}

The presence of sulfite in aqueous media can result in conversion of $\mathrm{SO}_{3}{ }^{2-}$ to $\mathrm{SO}_{2}$ gas through the following equilibria [33]:

$$
\begin{array}{lll}
\mathrm{SO}_{3}{ }^{2-}(\mathrm{aq})+\mathrm{H}_{2} \mathrm{O}(\mathrm{l}) \leftrightarrows \mathrm{HSO}_{3}{ }^{-}(\mathrm{aq})+\mathrm{OH}^{-}(\mathrm{aq}) & \mathrm{K}_{\mathrm{b}}=1.8 \times 10^{-7} \\
\mathrm{HSO}_{3}{ }^{-}(\mathrm{aq})+\mathrm{H}_{2} \mathrm{O}(\mathrm{l}) \leftrightarrows \mathrm{H}_{2} \mathrm{SO}_{3}(\mathrm{aq})+\mathrm{OH}^{-}(\mathrm{aq}) & \mathrm{K}_{\mathrm{b}}=1 \times 10^{-12} \\
\mathrm{H}_{2} \mathrm{SO}_{3}(\mathrm{aq}) \leftrightarrows \mathrm{H}_{2} \mathrm{O}(\mathrm{l})+\mathrm{SO}_{2}(\mathrm{~g}) &
\end{array}
$$

It is clear from this, however, that at $\mathrm{pH}$, these reactions should go to completion due to the loss of $\mathrm{SO}_{2}$ gas from the system (low $\left[\mathrm{OH}^{-}\right]$concentrations will favour products). However, if the sulfite were to completely convert to $\mathrm{SO}_{2}$ gas and be removed from the system, then the impact of sulfite would be expected to be negligible and the results should be indistinguishable from the control experiments. The 
$\mathrm{pH}$ of the reaction at the beginning and at the end was monitored to check the impact of sulfite conversion to $\mathrm{SO}_{2}$ and was found to be: $\mathrm{pH}$ initial $\sim 7.7, \mathrm{pH}$ final $\sim 6.8$. From these results we do not expect the sulfite to convert to $\mathrm{SO}_{2}$.

\section{RESULTS}

\subsection{Morphology and Conductivity}

The effect of sulfite on the precipitation of barium sulfate is best summarized by the images seen in Figure and 3. At $S=18.8$, sulfite ions do not appear to do much to the morphology of barium sulfate. There is some roughening in the presence of sulfite and the aspect ratio is slightly higher, but otherwise it is very similar to the control. This could be suggestive of the sulfite being removed from the system through the $\mathrm{SO}_{2}$ pathway.
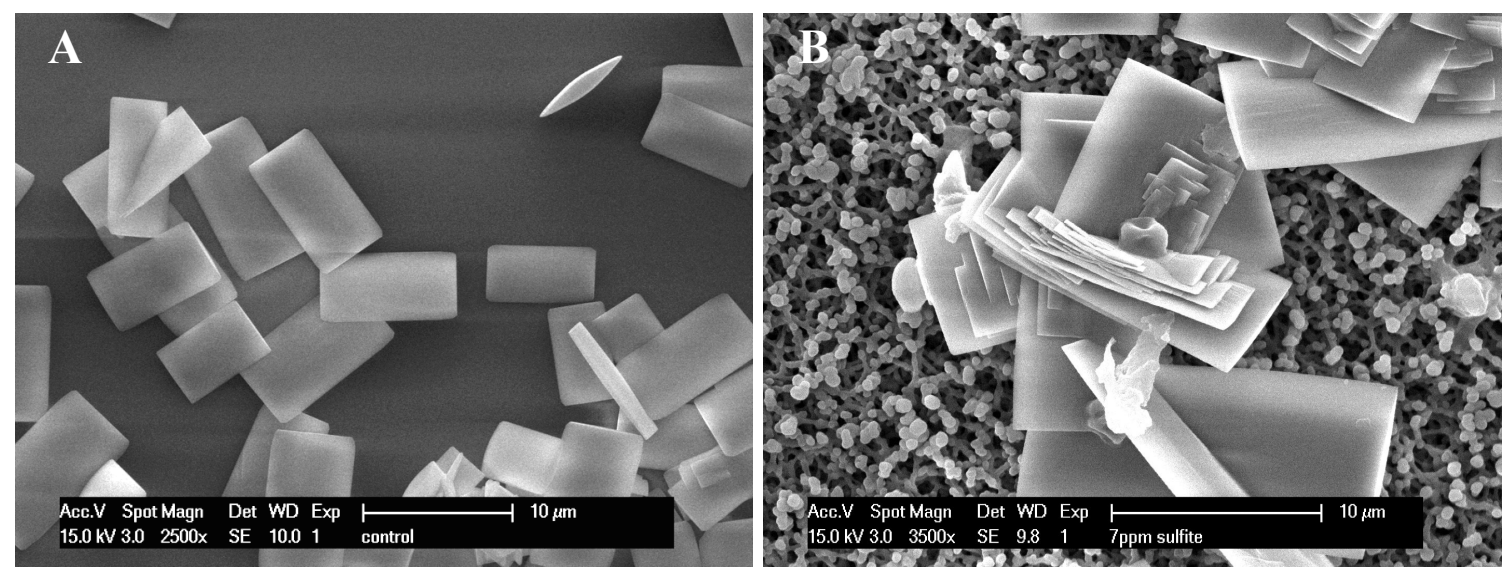

Figure 2. Barium sulfate formed at $\mathrm{S}=18.8$ in the presence of $\mathbf{A}$ ) control (barium sulfate only) and $\mathbf{B}$ ) sodium sulfite $(0.056 \mathrm{mM})$

When the supersaturation is lowered, the $c$-axis (relative to the other faces) length of the resultant barium sulfate was observed to increase. In the case of sulfite ions being present, this elongation occurs to a maximum and then the aspect ratio decreases once again (Figure $3 \mathrm{~b}$ and supplementary section, SFigure 1). At this lower $\mathrm{S}$ the system is not comparable to the control and does not suggest removal of the sulfite. The most probable cause of this is that the sulfite ion increases the nucleation rate. In a batch 
system, when nucleation increases fewer ions are left in solution for growth to occur. This can be further investigated through light scattering experiments (or turbidity as in this work) to ascertain if, indeed nucleation rates are impacted. Comparison of the morphology obtained in the presence of sulfite to that expected if all of the sulfite oxidized to sulfate shows that this cannot be a satisfactory explanation of the results (see supplementary section SFigure 2, and $S=8.5$ as determined by PHREEQC [27]).
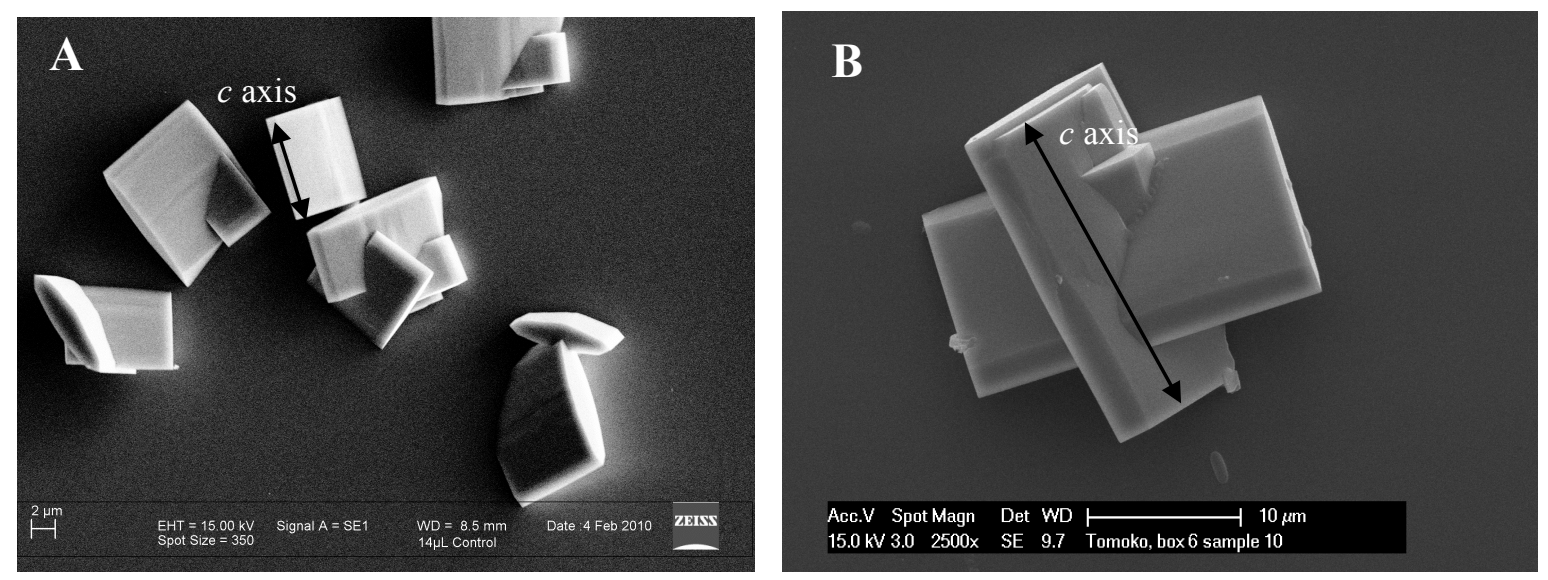

Figure 3. SEM images of barium sulfate particles formed at $\mathrm{S}=7$ and A) 0 B) $0.08 \mathrm{mM}$ sulfite ions

In contrast to the morphology results, the presence of the sulfite ions had a marked impact on the desupersaturation rate of barite (Figure 4), increasing the de-supersaturation rate at low concentrations. Thus, removal of sulfite from the system is, again, not plausible.

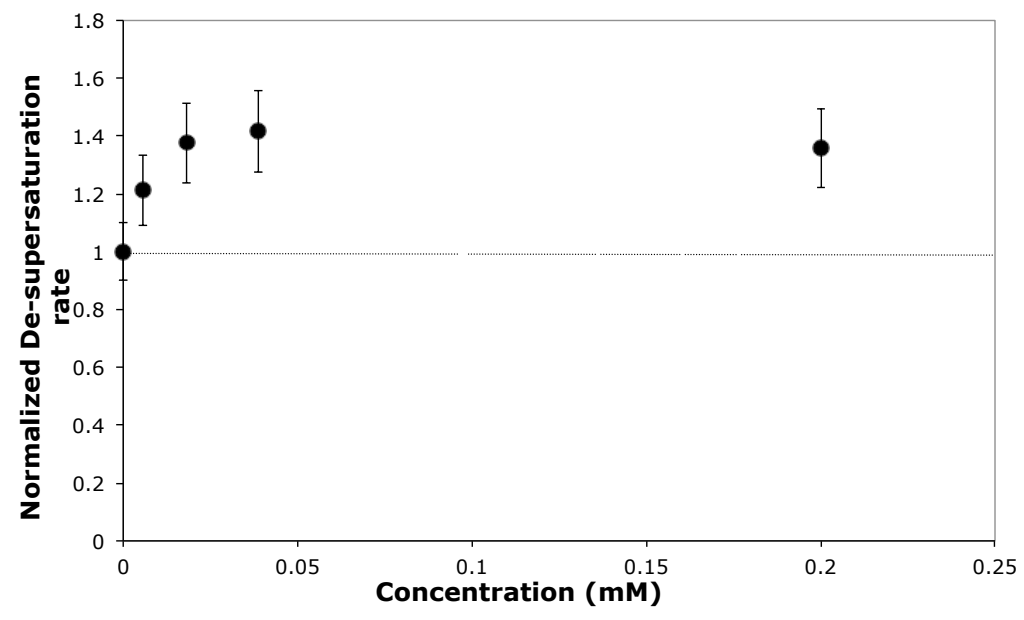


Complexation to barium ions could also be altering the supersaturation as the concentrations of these anions are increasing. Given that complexation will reduce the amount of free barium ions in solution, the 'control' would be a barium sulfate experiment at a lower supersaturation and presumably a lower de-supersaturation rate. Thus, if complexation is occurring for the sulfite case the effect of promotion is even greater than that shown here.

\subsubsection{Complete oxidation of sulfite comparison}

A more plausible mechanism for this observed promotion is that the sulfite oxidises to sulfate, thereby increasing the supersaturation. The de-supersaturation results for sulfite addition were, therefore, normalized to the expected de-supersaturation rate if all the species had oxidized to sulfate and increased the supersaturation. Firstly, the new supersaturation of the solution was calculated, based on how much sulfite was added (assuming complete oxidation), then the de-supersaturation rate of a control at the new supersaturation was determined from data at different $\mathrm{S}$ values (see supplementary information, SFigure 3). This new control value was used to normalize each data point in Figure 3 to give Figure 5. In addition, given that crystallization may be impacted on by the cation:anion ratio [15], another set of conductivity experiments (see supplementary information, SFigure 3) was also undertaken whereby the barium ion was kept constant but the sulfate concentration was increased to mimic the fact that if sulfite did oxidise it would increase the sulfate concentration only. Once again, the data were normalized to these new control values. 


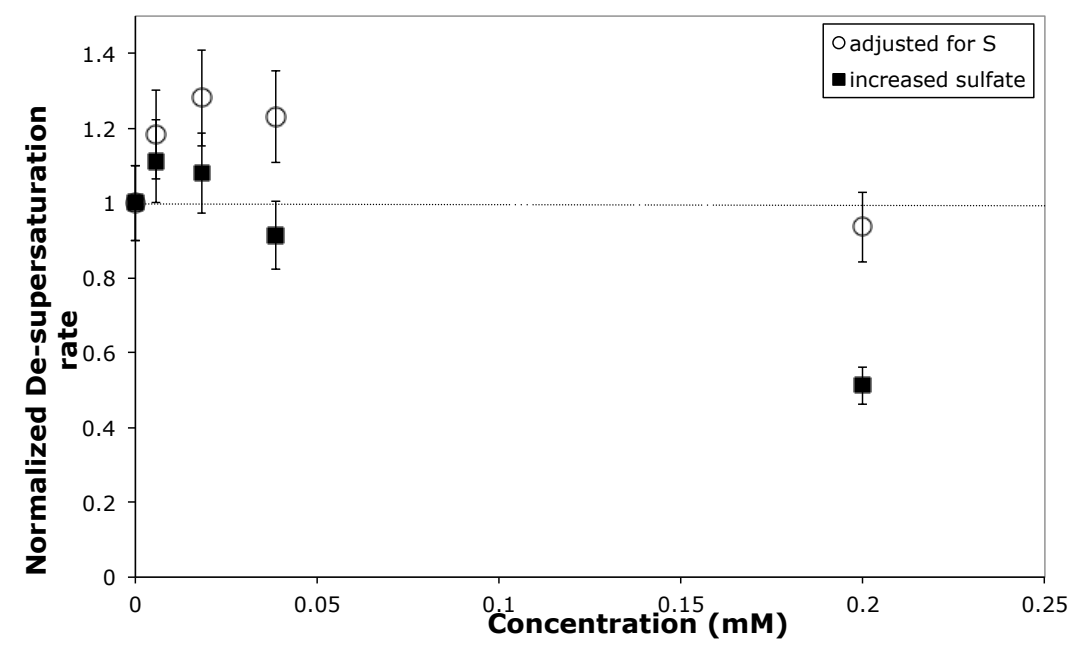

Figure 5. Adjustment of relative de-supersaturation rates for when sulfite is present based on increased supersaturation assuming either 1:1 ion ratio (open circles) or increased sulfate ion only (closed squares)

From this new set of data it is clear that oxidation of sulfite to sulfate can explain the impact of the sulfite ions on the conductivity results of barium sulfate crystallization when the increased sulfate level data is used at low concentrations of added sulfite. Interestingly, at high concentrations of added sulfite, it appears that the rate of de-supersaturation decreases. Thus, in this regime, neither conversion to sulfur dioxide nor oxidation to sulfate can explain the influence of sulfite. At these concentrations, sulfite acts as a crystallization inhibitor. Also, the conductivity data represents best the impact on the overall crystallization process and so the question still remains as to whether these ions impact on nucleation, growth or both.

\subsection{Impact on homogenous nucleation}

Increasing induction time suggests decreasing nucleation rates and light scattering methods such as turbidity can be used to determine induction times [29]. Looking at the turbidimetric data for impacts on the induction time, the absorbance of the barium sulfate crystallization solution is increasing above background levels at a shorter time with the increasing concentration of sulfite ions (Figure 6). Without further analysis, it appears that sulfite ions promote homogenous nucleation of barium sulfate. Again, formation of $\mathrm{SO}_{2}$ can be discounted. 


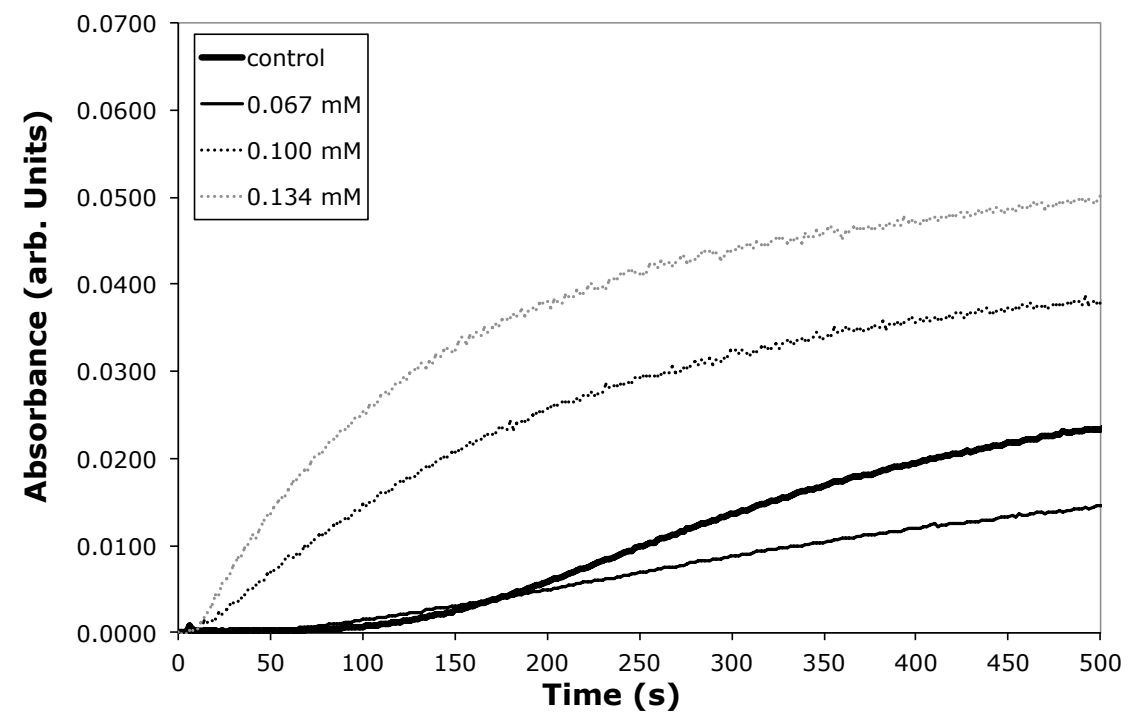

Figure 6. Turbidity curves (Absorbance versus time) for barium sulfate precipitation in the presence of varying sulfite concentration (control - thick black line, $0.067 \mathrm{mM}$ - thin black line, $0.1 \mathrm{mM}$ - dashed black line, $0.134 \mathrm{mM}$ - dashed grey line)

In order to properly determine the extent of homogenous nucleation promotion for sulfite ions, control turbidimetric runs were conducted with increased sulfate ion concentration to mimic complete oxidation (Figure 7). The results of these are presented below. The induction time appears to be slightly longer (as would be expected from an ion ratio perspective [15] when the sulfate ion is in excess compared to the control despite the slightly higher supersaturation that is present ( $\mathrm{S}=18.8$ to 22.9 ). From previous studies [25] there is an error in the induction time determination of \pm 50 seconds and this may account for some of the differences observed but the presence of sulfite showed much shorter induction times suggesting a higher nucleation rate than would be otherwise expected based on oxidation arguments. 


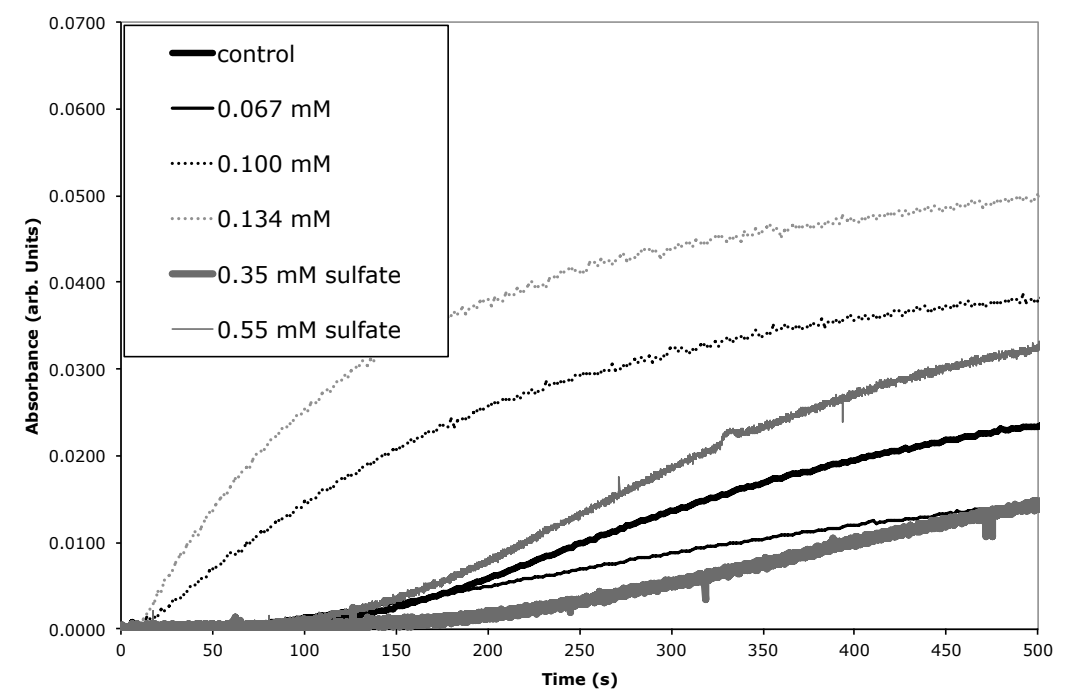

Figure 7. Absorbance versus time for barium sulfate crystallization in the presence of different sulfite concentrations (control - thick black line, $0.067 \mathrm{mM}$ - thin black line, $0.1 \mathrm{mM}$ - dashed black line, $0.134 \mathrm{mM}$ - dashed grey line) and comparison to additional sulfate ions being present. The $0.35 \mathrm{mM}$ sulfate has a longer induction time since excess sulfate $\left(\mathrm{Ba}^{2+} / \mathrm{SO}_{4}{ }^{2-}<1\right)$ is present. When $0.134 \mathrm{mM}$ sulfite oxidises completely this would be equivalent to $0.38 \mathrm{mM}$ sulfate.

\subsection{Impact on growth of the barite (001) face}

The AFM of barium sulfate growth on the (001) face in the presence and absence of sulfite ions confirms some of the mechanistic information already obtained. Figure shows some snapshot images during the in-situ growth of the (001) face of barium sulfate in the presence of sulfite ions. A schematic of the normal growth sector shape and the corresponding growth directions for pure barium sulfate on the (001) is shown superimposed in Figure $8 \mathrm{a}$. Since the $<100>$ is the slowest growing direction of the growth sector, this direction was chosen to reflect the impact of the sulfite ion on the growth rate. 


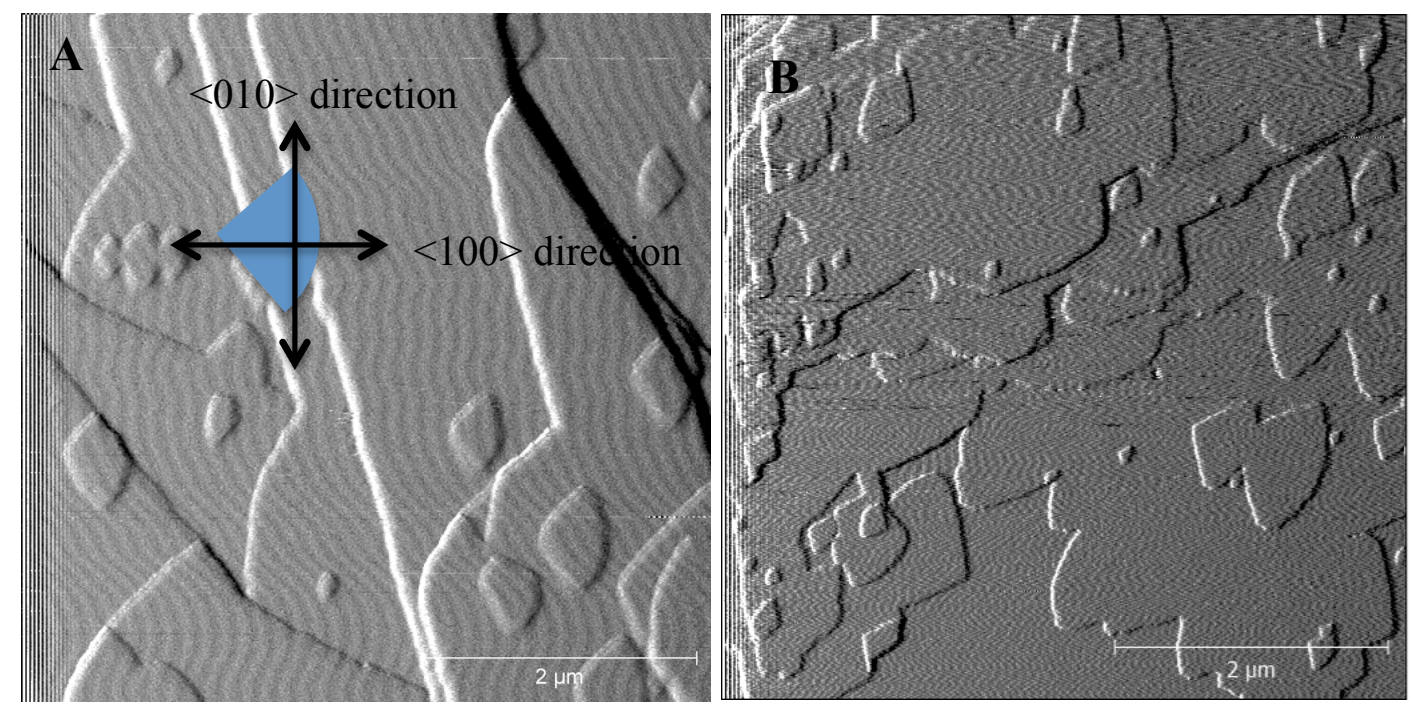

Figure 8. $5 \times 5 \mu \mathrm{m}$ AFM in-situ images (deflection mode) of the (001) growth at $\mathrm{S}=5$ in the presence of $\mathbf{A}) 0 \mathrm{mM}$ impurity (control) with a schematic showing the growth island and the directions associated with the growth island, and $\mathbf{B}$ ) $0.040 \mathrm{mM}$ sulfite

The presence of sulfite ions did not impact the sector shape of barium sulfate 2D nuclei (Figure $8 b$ ). No step pinning was observed in the presence of sulfite, however, this would only be expected if inhibition were to occur. The presence of sulfite also did not have a significant effect on the growth rate of the 2D nuclei (Figure 9a), which is surprising given that the range of concentrations would increase the supersaturation from $S=5$ (at $0 \mathrm{mM}$ sulfite) to $S=7.6$ (at $0.12 \mathrm{mM}$ sulfite).
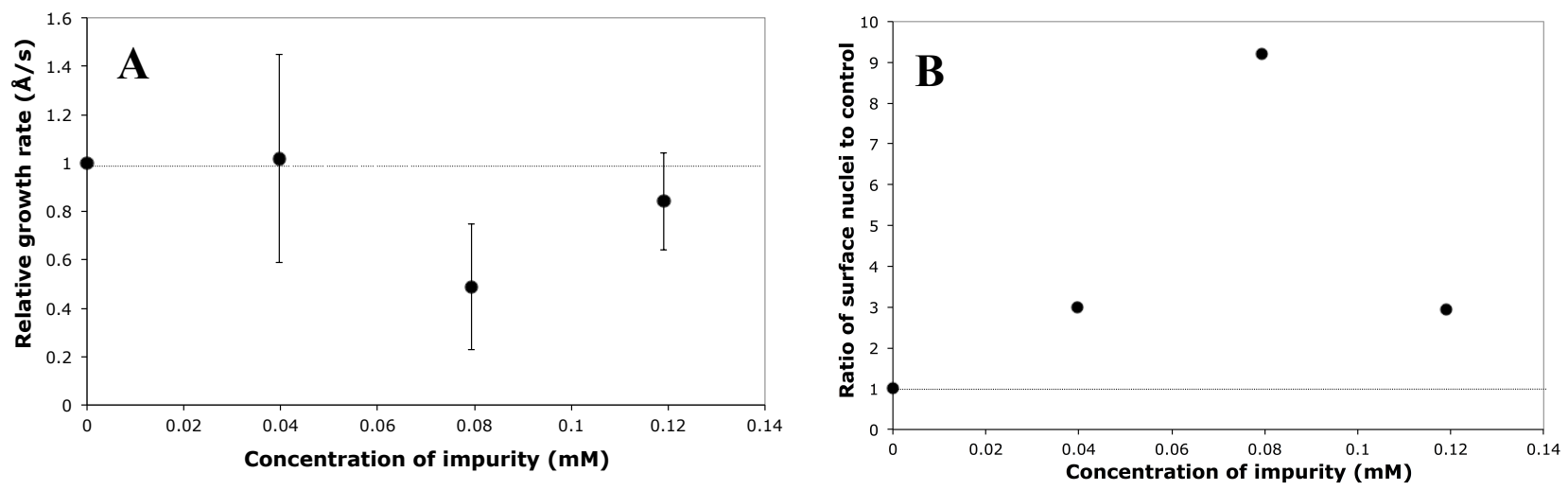

Figure 9. (A) Growth rate of barium sulfate in the $<100>$ direction relative to the control and (B) ratio of surface nuclei compared to control (on $5 \times 5 \mu \mathrm{m}$ scan)

This can be explained by a large number of new surface nuclei as seen in Figure $9 \mathrm{~b}$ and the supplementary figure, SFigure 4. The number of new nuclei formed increases with respect to the control 
and this would increase the number of step or kink sites available for the growth units to attach to, thereby limiting the growth rate.

These are the raw data rather than those adjusted for any oxidation. No comment is therefore made as to whether these are consistent with oxidation or not but it is interesting to note that the $2 \mathrm{D}$ nucleation rate significantly decreases at the highest sulfite concentration, closer to the control value and the rate shows an increase as would be expected based on the above kink site argument. This drop in 2D nucleation promotion could be the region where sulfite begins to act as an inhibitor.

\subsection{Promotion mechanism}

The presence of sulfite ions during barium sulfate crystallization shows that all of the results are inconsistent with the conversion of sulfite to sulfur dioxide but some results are consistent with oxidation to sulfate while others are not. Assuming oxidation was occurring, the oxidation process could be slow (in which case $\mathrm{S}$ is relatively unaffected) or fast (in which case $\mathrm{S}$ is affected). If oxidation is slow and does not impact on the supersaturation greatly, the newly formed sulfate ion should slightly decrease the nucleation rate [15], which is not what is observed in this case. If one assumes that the oxidation is fast and impacts on supersaturation we have compared the data where possible to the appropriate results based on this new supersaturation. A sulfate production rate of $0.0005 \mathrm{mM} / \mathrm{hr}$ is not significant when initial concentrations are of the order of $0.25 \mathrm{mM}(\sim 0.2 \%$ of the total). Thus, oxidation is not a plausible mechanism when the experiments are conducted over times frame of $<3$ hours (such as AFM where the data is collected continuously, conductivity where the experiment is over in 3 hours or turbidity where the experiment is complete after 1 hour). It is, therefore, more likely that the sulfite ion lowers a known kinetic energy barrier to barium sulfate crystallization. Possible energy barriers are: nucleation ( $\mathrm{S}$ is relatively static so this is not plausible) or the energy barrier to incorporation of the growth unit into the growing particle. The energy barrier to incorporation is made up of the barrier to desolvate the cation and anion and incorporation of these ions into the lattice which itself may have to desolvate. These different barriers cannot be assessed individually experimentally. However, modelling 
has shown that the rate-determining step in barium sulfate is barium ion desolvation and that this leads to a $c$-axis lengthening being observed $[13,17]$. Thus, it is proposed that the promotion in this case is due to the sulfite ion lowering the barrier to the de-hydration of the barium ion via weak interactions and this results in faster crystallization kinetics particularly along the $c$ axis $[13,17]$.

\section{SUMMARY}

The inorganic sulfite ions were shown to promote barium sulfate crystallization in terms of desupersaturation, at low concentrations. However, at this concentration the impact was effectively explained by assuming the complete oxidation of sulfite to sulfate. The impacts of sulfite ions on morphology, however, were not easily explained by oxidation. Here the aspect ratio of the particles formed was much higher than those expected even when oxidation was considered. Thus, growth of the (001) face appears to be promoted in the presence of sulfite ions based on the morphology results. Turbidity data shows that homogenous nucleation (3D) is also promoted in the presence of sulfite ions. Once again, oxidation did not fully explain the impacts.

The AFM analysis showed that the sulfite ion did not impact on surface nuclei shape. Thus, the primary mode of crystallization promotion for sulfite ions was to promote homogenous nucleation (from

turbidity data) and possibly also 2D nucleation (from AFM data and morphology). The combination of results and the inability of many of these to be explained by oxidation suggests that promotion is most likely to be occurring in addition to a small change in supersaturation over time. This promotion is most likely due to a lowering of the activation barrier to barium ion dehydration.

In conclusion, it can be seen that even simple inorganic ions, can have a profound effect on barium sulfate crystallization. Sulfite ion's conversion to sulfur dioxide did not explain any barium sulfate crystallization results. The presence of sulfite ions was shown to promote nucleation and as such is different to other inorganic, anionic promoters such as the monovalent ions shown to increase growth rates. 


\section{ACKNOWLEDGEMENTS}

We would like to acknowledge Dr. Thomas Becker for the use of the AFM facilities (Curtin Institute of Functional Materials and Interfaces, Dept. of Chemistry, Curtin University) and the John de Laeter Centre for use of the SEM, TEM, and XRD facilities. We thank the Museum of Western Australia (A. Bevan) for the mineralogical barium sulfate sample used in the AFM study - the sample origin of which was Westmorland, UK.

Funding:

This research did not receive any specific grant from funding agencies in the public, commercial, or notfor-profit sectors.

Supplementary Information: SEM images of barium sulfate at different supersaturations, desupersaturation 'control' data at different supersaturations for normalization, AFM images of barium sulfate in the presence of sulfite.

\section{REFERENCES.}

[1] K. Yamada, Light Metals, 1981, 31, 43-48.

[2] M. S. Antonious, Phosphorous, Sulfur, Silicon Relat. Elem., 1996, 112, 235-245.

[3] R. H. Hausler, Oil and Gas Journal, 1978, Sept 18, 146-154.

[4] A. Quddus and I. Allam, Desalination, 2000, 127, 219-224.

[5] K. S. Sorbie and N. Laing, in 6th International Symposium on oilfied Scale, Society of Petroleum Engineers Inc, Aberdeen Scottland, 2004, p. SPE 87470.

[6] F. Jones, M. Mocerino, M. I. Ogden, A. Oliviera and G. M. Parkinson, Crystal Growth \& Design, 2005, 5, 2336-2343.

[7] F. Jones, W. R. Richmond and A. L. Rohl, J. Phys. Chem. B., 2006, 110, 7414-7424.

[8] F. Jones, J. Clegg, A. Oliviera, A. L. Rohl, M. I. Ogden, G. M. Parkinson, A. M. Fogg and M. M. Reyhani, CrystEngComm, 2001, 40, 1-3.

[9] E. Barouda, K. D. Demadis, S. R. Freeman, F. Jones and M. I. Ogden, Crystal Growth \& Design, 2007, 7, 321-327.

[10] P. V. Coveney, R. J. Davey, J. L. W. Griffin, Y. He, J. D. Hamlin, S. Stackhouse and A. Whiting, J. Am. Chem. Soc., 2000, 122, 11557-11558.

[11] C. Garcia, G. Courbin, F. Ropital and C. Fiaud, Electrochimica Acta, 2001, 46, 973-985.

[12] S. Elhadj, E. A. Salter, A. Wierzbicki, J. J. De Yoreo, N. Han and P. M. Dove, Crystal Growth \& Design, 2006, 6, 197-201.

[13] S. Piana, F. Jones and J. D. Gale, CrystEngComm, 2007, 9, 1187 - 1191.

[14] U. Becker, P. Risthaus, D. Bosbach and A. Putnis, Molecular Simulation 2002, 28, 607-632.

[15] M. Kowacz, C. V. Putnis and A. Putnis, Geochimica et Cosmochimica Acta, 2007, 71, 51685179. 
[16] P. Risthaus, D. Bosbach, U. Becker and A. Putnis, Colloids and Surfaces. A., 2001, 191, 201214.

[17] S. Piana, F. Jones and J. D. Gale, J. Am. Chem. Soc., 2006, in press.

[18] A. J. Andara, D. M. Heasman, A. Fernandez-Gonzalez and M. Prieto, Crystal Growth \& Design, 2005, 5, 1371-1378.

[19] A. Fernández-González, R. Martín-Díaz and M. Prieto, Journal of Crystal Growth, 1999, 200, 227-235.

[20] N. Sánchez-Pastor, M. Kaliwoda, S. Veintemillas-Verdaguer and G. Jordan, American Mineralogist 2013, 98, 1235-1240.

[21] C. N. Baird and K. F. Taylor, Journal of Computational Chemistry, 1981, 2, 225-230.

[22] F. Jones, P. Jones, M. I. Ogden, W. R. Richmond, A. L. Rohl and M. Saunders, Journal of Colloid and Interface Science, 2007, 316, 553-561.

[23] F. Jones, A. Oliviera, G. M. Parkinson, A. L. Rohl, A. Stanley and T. Upson, Journal of Crystal Growth, 2004.

[24] F. Jones, A. Oliviera, G. M. Parkinson, A. L. Rohl, A. Stanley and T. Upson, Journal of Crystal Growth, 2004, 270, 593-603.

[25] F. Jones, A. Oliviera, A. L. Rohl, M. I. Ogden and G. M. Parkinson, CrystEngComm, 2006, 8, 869-876.

[26] F. Jones, A. Oliviera, A. L. Rohl, G. M. Parkinson, M. I. Ogden and M. M. Reyhani, Journal of Crystal Growth, 2002, 237-239, 424-429.

[27] D. L. Parkhurst and C. A. Appelo, Users guide to PHREEQC (version 2) - a computer program for speciation, batch reaction, one dimensional transport, and inverse geochemical calculations, U.S. Geological Survey Water-Resources Investigation Report, 1999.

[28] T. Radomirovic, P. Smith and F. Jones, Int. J. Mineral Processing, 2013, 118, 59-64.

[29] J. W. Mullin, Crystallization, Butterworth-Heinemann Publishers Ltd, London, 1993.

[30] F. Camacho, M. P. Páez, M. C. Jiménez and M. Fernández, Chemical Engineering Science, 1997, 52, 1387-1391.

[31] C. R. Martins, C. A. Cabral Neto, J. J. F. Alves and J. B. de Andrade, Journal of Brazilian Chemical Society, 1999, 10, 453-458.

[32] S. Tsunogai, Geochemical Journal, 1971, 5, 175-185.

[33] S. E. Schwartz and J. E. Freiberg, Atmospheric Environment, 1981, 15, 1129-1144. 